\title{
Estimation of thermal conductivity of short pastry biscuit at different baking stages
}

\author{
Chiara Cevoli, ${ }^{1}$ Angelo Fabbri, ${ }^{1}$ Simone Virginio Marai, ${ }^{2}$ Enrico Ferrari, ${ }^{2}$ Adriano Guarnieri ${ }^{1}$ \\ ${ }^{1}$ Department of Agricultural and Food Sciences, University of Bologna; \\ ${ }^{2}$ Department of Agricultural and Environmental Science, University of Milano, Italy
}

\begin{abstract}
Thermal conductivity of a food material is an essential physical property in mathematical modelling and computer simulation of thermal processing. Effective thermal conductivity of non-homogeneous materials, such as food matrices, can be determined experimentally or mathematically. The aim of the following research was to compare the thermal conductivity of short pastry biscuits, at different baking stages (60-160 min), measured by a line heat source thermal conductivity probe and estimated through the use of thermo-physical models. The measures were carried out on whole biscuits and on powdered biscuits compressed into cylindrical cases. Thermal conductivity of the compacted material, at different baking times (and, consequently at different moisture content), was then used to feed parallel, series, Krischer and Maxwell-Eucken models.

The results showed that the application of the hot wire method for the determination of thermal conductivity is not fully feasible if applied directly to whole materials due to mechanical changes applied to the structure and the high presence of fats. The method works best if applied to the biscuit component phases separately. The best model is the Krischer one for its adaptability. In this case the value of biscuit thermal conductivity, for high baking time, varies from 0.15 to 0.19 $\mathrm{Wm}^{-1} \mathrm{~K}^{-1}$, while the minimum, for low baking time, varies from 0.11 to $0.12 \mathrm{Wm}^{-1} \mathrm{~K}^{-1}$. These values are close to that reported in literature for similar products.
\end{abstract}

Correspondence: Chiara Cevoli, Department of Agricultural and Food Sciences (DISTAL), University of Bologna, P.zza Goidanich 60, 47521 Cesena (FC), Italy.

Tel.: +39.0547.338151 - Fax: +39.0547 .382348 .

E-mail: chiara.cevoli3@unibo.it

Key words: thermal conductivity, bakery products, biscuit, mathematical models.

Received for publication: 4 April 2014.

Accepted for publication: 9 June 2014.

(C) Copyright C. Cevoli et al., 2014

Licensee PAGEPress, Italy

Journal of Agricultural Engineering 2014; XLV:232

doi:10.4081/jae.2014.232

This article is distributed under the terms of the Creative Commons Attribution Noncommercial License (by-nc 3.0) which permits any noncommercial use, distribution, and reproduction in any medium, provided the original author(s) and source are credited.

\section{Introduction}

Numerical modelling has become a major tool for understanding and predicting complex processing phenomena, permitting the use of time/space/temperature/moisture-dependent variables instead of average values of thermo-physical properties of foods (Juliano et al., 2011).

Thermal conductivity of a food material is an essential physical property in mathematical modelling and computer simulation of thermal processing. The availability of such a model could be a useful tool for process parameters optimisation, e.g. in cooking, freezing, drying or pasteurisation. A substantial number of thermal conductivity data for minimally processed food such as meat, fruit and vegetable is reported in literature (Ahmed and Rahaman, 2009). Given that thermal conductivity of foods is affected mainly by three factors: structure, composition and processing conditions, it is difficult to find data for processed food products. Structural factors consist of porosity, pore size, shape and distribution, and distribution of different phases, such as air, water, ice, and solids. As for composition, water content plays a significant role due to its high thermal conductivity value compared to other components. Processing factors consist of temperature history, pressure, mass transfer and energy transfer (Rahman and Al-Saidi, 2009).

A solid material contains pores, which may be either completely isolated or interconnected with each other (Carson et al., 2006). These materials should be divided in two classes: external porosity materials (e.g. particulates and grains) and internal porosity materials (e.g. bakery products) (Carson et al., 2005).

Effective thermal conductivity of non-homogeneous materials, such as food matrices, can be determined experimentally or mathematically. Methods used for thermal conductivity measurements may be divided into two categories: steady state and transient techniques (Murakami and Okos, 1989; Mohesenin, 1980).

In the steady-state methods, where it is easy to control experimental conditions, the heat flux is measured by an induction coil or by an electrical heater resistance. However the process has limitations in measuring heat transfer of food materials since it takes a long time to reach the steady state. This is often not compatible with foods, which are stable for a short time. Particularly the moisture distribution can significantly vary in time. On the other hand, transient methods are the most commonly used for food materials, mainly because of short measurement time, relative independence from the sample geometry, limited temperature rise of sample and ease of use. Given that the sample results minimally modified, it can be used either to determine thermal conductivity at several temperatures or to carry out several replicates of the measurement at same conditions (Nesvadba, 1982). The most widely used instrument is the hot wire thermal conductivity probe. This instrument is not suitable for foods, which have a heterogeneous phase distribution because the measurement is localised. 
In the absence of experimental data, estimation may be obtained mathematically by thermal conductivity models. A large number of models used for the effective thermal conductivity determination of composite or heterogeneous materials is reported in literature (Carson, 2006), but it is not always clear which model is appropriate for a given food product. The most important models are series, parallel, Maxwell, Kopelman and Krischer equations (Rahman and Al-Saidi, 2009).

Different data and prediction models dealing with thermo-physical properties of bakery products are reported in literature (Christenson $e t$ al., 1988; Rask, 1989; Baik et al., 2001; Carson, 2006). In particular Baik et al. (2001) reviewed prediction models, new and common measurement techniques and data on thermo-physical properties of many bakery products. Furthermore, due also to the wide variety of bakery products (bread, cake, muffin, biscuit, cracker, tortilla, etc.) varying in porosity, compositions and processing conditions, it has been suggested that for greater accuracy thermal properties should be measured for each individual case (Rask, 1989).

The aim of the following research was to compare the thermal conductivity of short pastry biscuits, at different baking stages (60-160 min), measured by a line heat source thermal conductivity probe and estimated through the use of simple thermo-physical models (Series, Parallel, Maxwell-Eucken and Krischer).

\section{Materials and methods}

\section{Setup of the samples preparation}

The experimental set up is shown in Figure 1. A standard recipe for short pastry was used with the following ingredients: $500 \mathrm{~g}$ wheat flour '00' [Molino F.lli Chivazza S.p.A., Casalgrasso (CN), Italy], $250 \mathrm{~g}$ butter [CARREFOUR, Bolzano Vicentino (VI), Italy], 125 g sugar (Sudzucker, Mannheim, Germany) and 2 eggs weighing about 65 g. Ingredients were mixed in the multi-function Krups 3 MIX 7007 ProMetal food processor (Krups, Offenbach am Main, Germany) equipped with spiral arms for $3 \mathrm{~min}$ at $600 \mathrm{rpm}$ and 16 revolutions per min, followed by $7 \mathrm{~min}$ at $900 \mathrm{rpm}$ and 22 revolutions per minute. Dough was stored at $4^{\circ} \mathrm{C}$ for $15 \mathrm{~h}$ before molding and baking.

Biscuits were formed in a stainless steel AISI 304 cylindrical mold (diameter $9 \mathrm{~cm}$, height $3 \mathrm{~cm}$ ) and taken to room temperature before the thermal treatment.

Dough samples were baked in an electrical natural convection static oven [M20-MPN-INSTRUMENTS, Bernareggio (MB) Italy], $0.3 \mathrm{~m}$ high, $0.3 \mathrm{~m}$ wide and $0.24 \mathrm{~m}$ long. Baking was carried out at $180^{\circ} \mathrm{C}$ for various times: $60,80,100,120,140$ and 160 min. A biscuit was placed in the centre of the baking chamber, on a metal net, to achieve a homogenous distribution of heat and mass fluxes. For each time, three biscuits were baked.

To study structural changes during baking, baked biscuits were cut with a smooth blade along their diameter and were photographed by a high resolution handheld microscope (ProScope HR; Bodelin Technologies, Lake Oswego, OR, USA) with a 50X lens in different position.

Baked biscuits were grinded in a blender until their particle sizes were homogeneous. Moisture content was measured on milled biscuits with an infrared moisture analyser (Sartorius MA100, Goettingen, Germany) with the following analysis parameters: $\mathrm{T}=130^{\circ} \mathrm{C}$, automatic stop when the gradient is less than $0.1 \%$ in $300 \mathrm{~s}$. The data are presented as the mean value of 3 biscuits for each baking time.

Powdered biscuits were compressed into cylindrical cases (diameter $3 \mathrm{~cm}$, height $11 \mathrm{~cm}$ ) equipped with a piston and an air vent valve.
Compression force was $200 \mathrm{~N}(283 \mathrm{kPa})$, applied with an electromechanical press (Criterion, MTS System Corporation, Eden Prairie, MN, USA) equipped with a $500 \mathrm{~N}$ load cell.

\section{Thermal conductivity measurements}

Thermal conductivity of the biscuits was measured using the commercial thermal properties analyser, KD2 (Decagon Devices Inc. Pullman, WA, USA). The probe consists of a wire heated by the Joule effect ( $60 \mathrm{~mm}$ long and $1.28 \mathrm{~mm}$ diameter) and a thermistor in the middle of the wire. To carry out the measurement, the controller begins by heating the probe for $30 \mathrm{~s}$ and then calculates thermal characteristics.

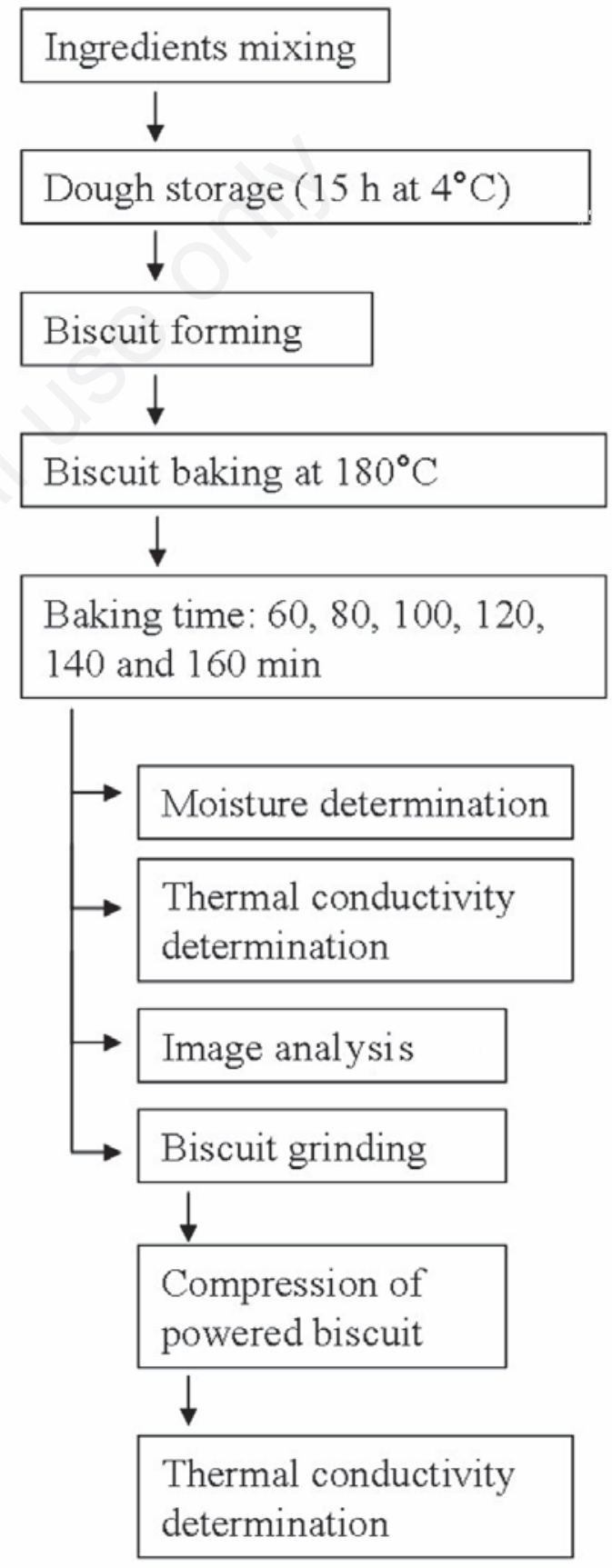

Figure 1. Flow chart of the experimental setup. 
The instrument was calibrated using distilled water and ethylene glycol before use. The sensor is based on the transient model of radial heat conduction in a homogeneous and isotropic medium.

The wire probe was completely inserted radially in the middle of the biscuit. The measurements were carried out in triplicate on three biscuits (nine moisture measurements in total) for each baking step (different moisture content) and on the powdered biscuits, compacted in the plastic case. The exact placement of the probe within the whole and compacted biscuit is reported in Figure 2.

Thermal conductivity of compacted material, at different moisture concentrations, was then used to feed thermal conductivity models described in the next section.

\section{Thermal conductivity models}

Biscuits are internal porosity materials, characterised by air bubbles distributed more or less uniformly throughout the matrix.

Different types of theoretical models have been developed by assuming various distributions of component phases. The most recurrent models present in literature and used in this work are: series, parallel, Krischer and Maxwell-Eucken. Series and parallel models define minimum and maximum theoretical limits of thermal conductivity for a twophase system. In the series model, components are conceptually aligned perpendicularly to the heat flow, while in the parallel, one of them is aligned along the same direction of the heat flow. The following equations describe these two models (Rahman and Al-Saidi, 2009):

$$
\begin{gathered}
k_{s}=\frac{1}{\sum_{i} \varepsilon_{i} / k_{i}} \\
k_{p}=\sum_{i} k_{i} \varepsilon_{i}
\end{gathered}
$$

where:

$\varepsilon_{i}$ is the volume fraction of $i$ th component phase (dispersed or continuous);

$k_{i}$ is the thermal conductivity of $i$ th phase (dispersed or continuous) $\left[\mathrm{Wm}^{-1} \mathrm{~K}^{-1}\right]$;

$k_{s}$ is the effective thermal conductivity of composite medium determined by the series model $\left[\mathrm{Wm}^{-1} \mathrm{~K}^{-1}\right]$;

$k_{p}$ is the effective thermal conductivity of composite medium determined by the parallel model $\left[\mathrm{Wm}^{-1} \mathrm{~K}^{-1}\right]$.

Krischer (1963) proposed an equation based on the combination of parallel and series models by a blending factor, named phase distribution factor $(f)$. This factor acts as a weighing factor between the extreme cases (parallel and series) and depends only on the sample structure. The following equation describes the Krischer's model:

$$
k_{f}=\frac{1}{\frac{1-f}{k_{p}}+\frac{f}{k_{s}}}
$$

where:

$k_{f}$ is the effective thermal conductivity of the composite medium determined by Krischer model $\left[\mathrm{Wm}^{-1} \mathrm{~K}^{-1}\right]$. When $f$ is zero, Krischer's model is reduced to the Parallel model, and when $f$ is unity Krischer's model is reduced to the Series model. Therefore this model may be expected to provide acceptable predictions of the thermal conductivity for the porous foods, provided a suitable value of $f$ was chosen. Unless data for the $f$ value is present in literature, this parameter must be determined experimentally, stating the great variability in formulation, structure and volumetric composition of the bakery products.
For a two-component food system consisting of a dispersed and continuous phase, an equation based on the dielectric theory had been developed by Maxwell (Maxwell, 1904) and then adapted by Eucken (Eucken, 1940). Effective thermal conductivity by the Maxwell-Eucken model is defined as:

$$
k_{m}=k_{c}\left(\frac{2 k_{c}+k_{d}-2 \varepsilon_{d}\left(k_{c}-k_{d}\right)}{2 k_{c}+k_{d}+\varepsilon_{d}\left(k_{c}-k_{d}\right)}\right)
$$

where:

$\varepsilon_{d}$ is the volume fraction of dispersed phase;

$k_{c}$ is the thermal conductivity of continuous phase $\left[\mathrm{Wm}^{-1} \mathrm{~K}^{-1}\right]$;

$k_{d}$ is the thermal conductivity of dispersed phase $\left[\mathrm{Wm}^{-1} \mathrm{~K}^{-1}\right]$;

$k_{m}$ is the effective thermal conductivity of composite medium determined by Maxwell-Eucken model $\left[\mathrm{Wm}^{-1} \mathrm{~K}^{-1}\right]$; .

In our case, the conductivity of the continuous phase is represented by the thermal conductivity of compacted material, while the conductivity of dispersed phase, is described by the thermal conductivity of the air.

Volume fractions of the continuous phase were determined by the ratio between the density of biscuit and the density of the compact material related. Symmetrically the dispersed phase volume fraction is measured as ratio between the density of the compact material and the whole biscuit density, corresponding to porosity.

The density of the biscuits were calculated by the ratio between weight (solid plus water) and volume. For the determination of volume, each biscuit has been photographed with a digital camera Fujifilm FinePix $6800 \mathrm{Z}$ oom, both in front view and side view. The biscuit was considered as a cylinder topped by a paraboloid, the heights in 9 specific positions were taken with a digital caliper. Nine point, at the same distance, where taken on two perpendicular diameters.

The heights data were fitted in a parabola to determine the volume of the paraboloid as:

$$
V=\int_{0}^{2 \pi} \int_{0}^{r_{b}}\left[\left(a r^{2}+b\right) \cdot r d r\right] d \omega
$$

where $r_{b}$ is the radius of the biscuit, $a$ and $b$ are the fitted parameters of parabola. The determination coefficient $R^{2}$ for the worst case was 0.996 .

The density of compacted material was calculated as ratio between weight (solid plus water) and volume, measured as volume of cylindri-

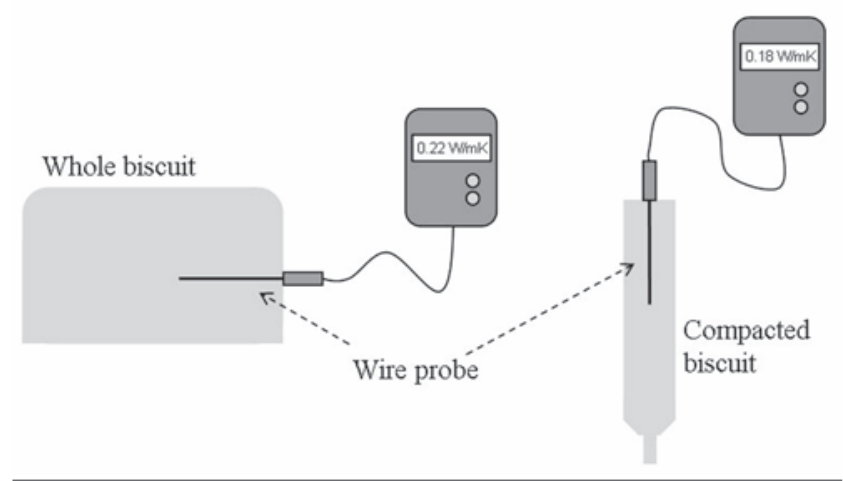

Figure 2. Schematic representation of placement of the probe within the whole and compressed biscuits. 
cal case. Differences between physical parameters of whole and compacted biscuits for different baking times were statistically characterised with ANOVA test (post-hoc: Tukey's test, P-level<0.05).

\section{Results and discussion}

Moisture content, density of the whole and compacted biscuits and volume fractions of the component phases of biscuit, as function of baking time, are reported in Table 1. The same lowercase letters show not significant difference between the mean of the samples baked for different time (P-level<0.05). Moisture content decreases by about $88 \%$ during baking (passing from 19.3 to $2.23 \%$ ), while densities of 40.51 and $34.65 \%$ for the whole and compacted biscuits, respectively.

During the first 60 min of baking, an significantly increase of dispersed phase volume was observed. After that, probably the baking reactions cause a structure compaction and, as a consequence, the fraction of dispersed phase (air) decreases. However, the reduction is weak. With the baking time the water go away and biscuit volume decrease: these two factors made whole biscuit density decrease slightly and porosity decrease strongly. The difference between density of whole biscuit and of compacted one is reduced.

The photos presented in Figure 3 show internal structure of the biscuit and the relationship between continuous and dispersed phases as a function of the baking time and of the position inside the biscuit. One can observe an irregular alveolar structure inside the biscuit. According to the data previously discussed, the presence of air in the dough, after 60 min of baking, decreases with the advance of dehydration, in particular for the crust zone and for higher baking times. Considering Figure 3 even without an automated image analysis process, with some difficulties, it is possible to distinguish by eyes that the dimension and number of air spaces are greater for the initial baking time.

The measurement performed on the biscuit compacted is not a measure of true density, but a simple measure of the material density. The material density is measured experimentally when the material has been thoroughly broken into small pieces to guarantee a small amount of pores (Michailidis et al., 2009). Accordingly the material density tends to be smaller than true density depending on the pieces size and on the intensity of compaction, therefore we are not totally sure that the material is absolutely free of voids. In addition the thermal treatment of food product at temperature over $70^{\circ} \mathrm{C}$ can reduce particle density (Stroshine, 2004a) for this reason the density of compacted material may decrease during cooking. As a consequence we are confident that the calculated continuous and dispersed phases volume fractions can be acceptable, and moreover acceptably close to ideal data.

Values of thermal conductivity, at various moisture contents, deter- mined by line probe method are reported in Figure 4. As reported by literature, thermal conductivity of compacted biscuits is strongly dependent on the moisture content (Rahman and Al-Saidi, 2009). Particularly it ranges from 0.12 to $0.27 \mathrm{Wm}^{-1} \mathrm{~K}^{-1}$, on the other hand thermal conductivity of the whole biscuit is less affected by the moisture ranging from 0.20 to $0.23 \mathrm{Wm}^{-1} \mathrm{~K}^{-1}$. For all baking times, the insertion of the probe, causes a structural change within the biscuit, induced by the needle. Furthermore an overcoating of the probe by butter fat were observed. As reported by Rask (1989), insertion of a probe into an unstable structure, as a dough and partly baked products, may produce the structure rupture close to the probe giving rise to false values. For the whole biscuits, the effect of fat is so heavy that hides the effect of moisture, as shown by the low inclination of the line (Figure 4), meaning a substantial independence of the conductivity from the moisture content. In our study, measured thermal conductivity probably was strictly influenced by thermal conductivity of fat matrix. Indeed thermal conductivity of the butter is about $0.2 \mathrm{Wm}^{-1} \mathrm{~K}^{-1}$ (Ramaswamy et al., 2007; Stroshine, 2004b; Barbosa-Canovas and Ibarz, 2002; Watson, 1975). Some authors circumvent the problem by surrounding the probe with whole biscuits. Unfortunately this solution is not applicable in our case because of material friability and roughness of the surface.

Thermal conductivity of whole biscuits is characterised by a linear behaviour $\left(\mathrm{R}^{2}=0.964\right)$, while the behaviour of the compacted biscuits is exponential $\left(R^{2}=0.964\right)$. For moisture content up to about $12 \%$ d.b., whole biscuits show the highest value of conductivity. The moisture is used here as an index representative of baking stage. Anyway the mois-

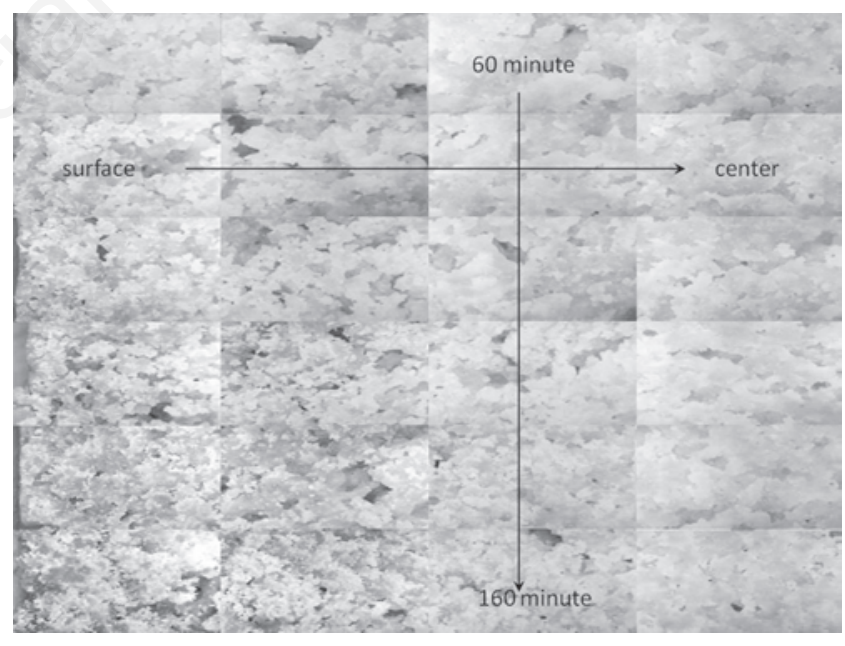

Figure 3. Photos of internal structure of the biscuit as function of baking time and position inside the biscuit.

Table 1. Biscuit parameters as function of baking time (standard deviation in brackets).

\begin{tabular}{lccccc} 
Baking time (min) & Moisture (\%) & $\begin{array}{c}\text { Biscuit density } \\
\left(\mathrm{kg}^{3} / \mathrm{m}^{3}\right)\end{array}$ & $\begin{array}{c}\text { Compacted biscuit } \\
\text { density }\left(\mathrm{kg} / \mathrm{m}^{3}\right)\end{array}$ & $\begin{array}{c}\text { Continuous phase } \\
\text { volume fraction }\end{array}$ & $\begin{array}{c}\text { Dispersed phase } \\
\text { volume fraction }\end{array}$ \\
\hline 0 & $19.13(0.63)^{\mathrm{a}}$ & $1337.16(6.25)^{\mathrm{a}}$ & $1337.16(6.25)^{\mathrm{a}}$ & $1^{\mathrm{a}}$ & $0^{\mathrm{a}}$ \\
60 & $13.13(0.45)^{\mathrm{b}}$ & $825.96(7.12)^{\mathrm{b}}$ & $1035.82(6.37)^{\mathrm{b}}$ & $0.797(0.012)^{\mathrm{b}}$ & $0.203(0.012)^{\mathrm{b}}$ \\
\hline 80 & $10.6(0.90)^{\mathrm{c}}$ & $839.97(8.32)^{\mathrm{c}}$ & $1011.65(12.63)^{\mathrm{c}}$ & $0.830(0.029)^{\mathrm{c}}$ & $0.170(0.0029)^{\mathrm{c}}$ \\
100 & $6.74(0.52)^{\mathrm{d}}$ & $820.59(9.45)^{\mathrm{b}}$ & $956.36(5.96)^{\mathrm{d}}$ & $0.858(0.031)^{\mathrm{c}, \mathrm{d}}$ & $0.142(0.031)^{\mathrm{c}, \mathrm{d}}$ \\
\hline 120 & $5.21(0.59)^{\mathrm{e}}$ & $799.15(3.63)^{\mathrm{d}}$ & $917.22(15.62)^{\mathrm{e}}$ & $0.871(0.025)^{\mathrm{d}}$ & $0.129(0.025)^{\mathrm{d}}$ \\
140 & $3.51(0.24)^{\mathrm{f}}$ & $794.18(4.65)^{\mathrm{d}}$ & $909.16(10.53)^{\mathrm{e}}$ & $0.873(0.026)^{\mathrm{d}}$ & $0.127(0.026)^{\mathrm{d}}$ \\
\hline 160 & $2.23(0.39)^{\mathrm{g}}$ & $795.44(3.87)^{\mathrm{d}}$ & $873.79(8.52)^{\mathrm{f}}$ & $0.911(0.022)^{\mathrm{e}}$ & $0.089(0.022)^{\mathrm{e}}$ \\
\hline
\end{tabular}


ture variations are bigger than porosity's.

Values of thermal conductivity calculated by Krischer model, at various moisture contents and distribution factor $(f)$, are reported in Figure 5. As can be seen, variation of thermal conductivity is very limited at high $f$ value (0.9-0.7). In fact for high $f$ value, the conductive model tends to series one, as a consequence effective thermal resistance is the sum of air and compacted biscuit resistance. Being the former much higher than the latter, even a significant variation of the second term can cause a very limited variation of the total resistance.

A number of studies have correlated distribution factor $(f)$ as a function of the composition for different foods, however these correlations of $f$ are dependent on additional empirical constants and, because $f$ is determined empirically, the correlations cannot be used for food products that were not included in the dataset used to derive the correlation (Carson et al., 2006).

Considering that thermal conductivity values measured on the whole biscuit are not reliable due to butter fat effect, the optimal $f$ value was determined comparing bibliographic data concerning different kind of biscuits (Sanayei et al., 2010; Reye et al., 2006; Tavman and Tavman, 1999; Christenson et al., 1988; Rask, 1989; Standing, 1974) and thermal conductivity of compacted biscuits. Unfortunately literature data was available only for completely baked biscuits or dough, related to a specific moisture content. But, starting from the thermal conductivity of water and dried biscuit, using the Krisher model it was possible to estimate the relationship between conductivity and moisture content, simply fitting measured data by a minimum least squares technique. Particularly, on the basis of previous literature considerations, a distribution factor values between 0.1 and 0.3 was selected. In this case the maximum value of thermal conductivity varies from 0.15 to $0.19 \mathrm{Wm}^{-1}$ $\mathrm{K}^{-1}$, while the minimum varies from 0.11 to $0.12 \mathrm{Wm}^{-1} \mathrm{~K}^{-1}$.

In particular Standing (1974) estimated thermal conductivity in cooked biscuits using a guarded hot plate steady-state process, for two positions, obtaining an average value of about $0.12 \mathrm{Wm}^{-1} \mathrm{~K}^{-1}$. This value is very similar to that calculated through the use of the Krischer model with $0.1<f<0.3$, at lowest moisture contents, even if for the present study the hot plate steady-state method is not applicable because of the change in biscuit moisture content during thermal stabilisation.

Values of thermal conductivity, at various moisture contents, determined by different models are reported in Figure 6. In particular Parallel, Series, Krischer $(f=0.3)$ and Maxwell-Eucken are shown. It can be see that parallel and series models define the upper and lower bounds for thermal conductivity. As might be expected, thermal conductivity values determined by Maxwell-Eucken model are very near to those determined by Parallel model and ranged from 0.12 to $0.21 \mathrm{Wm}^{-1}$ $\mathrm{K}^{-1}$. Indeed the Krischer model is popular because, unlike other more rigid models, it can be fitted to thermal conductivity data by suitable adjustment of $f$ and therefore it can often perform better than the other models.

\section{Conclusions}

The application of the hot wire method for the determination of thermal conductivity at different baking stages, in the specific biscuits here considered, is not fully feasible if applied directly to whole materials, because of mechanical changes applied to the structure and the high presence of fats. Uncertainty remains in choosing the best model for porous materials. In this specific case the best model is the Krischer one for its adaptability, but the $f$ parameters has to be evaluated. Comparing the literature data, related to complete baked biscuits, a distribution factor value between 0.1 and 0.3 was selected. In this case the value of biscuit thermal conductivity, for high baking time, varies from

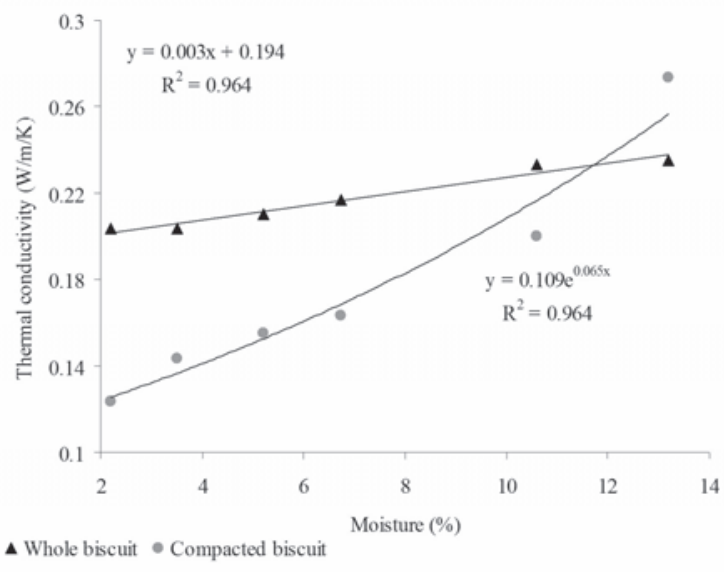

Figure 4. Thermal conductivity determined by the line probe, at various moisture contents.

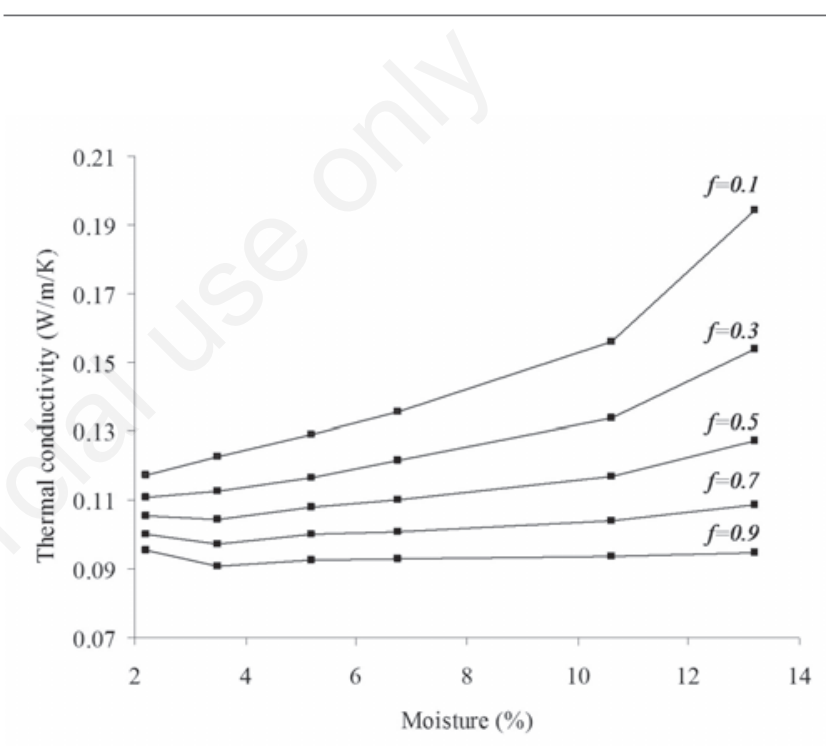

Figure 5. Thermal conductivity calculated by Krischer model, at various moisture contents and distribution factor $(f)$.

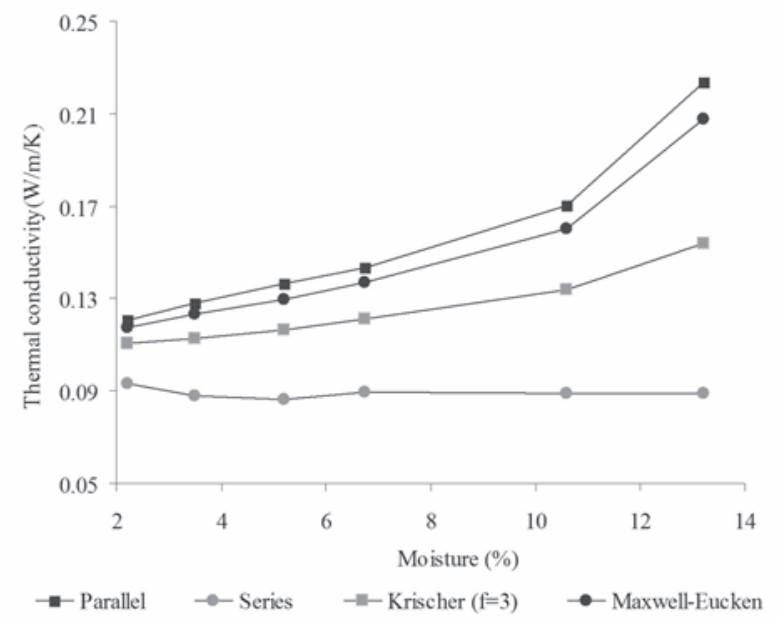

Figure 6. Thermal conductivity calculated by Parallel, Series, Krischer $(f=0.3)$ and Maxwell-Eucken models. 
0.15 to $0.19 \mathrm{Wm}^{-1} \mathrm{~K}^{-1}$, while the minimum, for low baking time, varies from 0.11 to $0.12 \mathrm{Wm}^{-1} \mathrm{~K}^{-1}$.

\section{References}

Ahmed J., Rahman M.S. 2009. Thermal conductivity measuremnt of food. In: M.S. Rahman (ed.), Food properties handbook. CRC Press, Boca Raton, FL, USA, pp 548-580.

Baik O.D., Marcotte M., Sablani S.S., Castaigne F. 2001. Thermal and physical properties of Bakery products. Crit. Rev. Food Sci. Nutr. 41:321-52.

Barbosa-Canovas G.V., Ibarz A. 2002. Thermal properties of food. In: G.V. Barbosa-Canovas and A. Ibarz (eds.), Operations in food engineering. CRC Press, Boca Raton, FL, USA, pp 309-320.

Carson, J.K. 2006. Review of effective thermal conductivity models for foods. Int. J. Refrig. 29:958-67.

Carson J.K., Lovatt S.J., Tanner D.J., Cleland A.C. 2005. Thermal conductivity bounds for isotropic, porous materials. Int. J. Heat Mass. Transf. 48:2150-8.

Carson J.K., Lovatt S.J., Tanner D.J., Cleland A.C. 2006. Predicting the effective thermal conductivity of unfrozen, porous foods. J. Food Eng. 75:297-307.

Christenson M.E., Tong C.H., Lund D.B. 1988. Physical properties of baked products as function of moisture and temperature. J. Food Process Pres. 13:201-17.

Eucken A. 1940. Allgemeine Gesetzmässigkeiten für das Wärmeleitvermögen verschiedener Stoffarten und Aggregatzustände. Forsch. Ingenieurwes. 11:6-20.

Juliano P., Trujillo F.J., Barbosa Canovas G.V., Knoerzer K. 2011. The need for thermophysical properties in simulating emerging food processing technologies. In: Knoerzer K., Juliano P., Roupas P., and Versteeg C. (eds.), Innovative food technologies: advances in multiphysics simulation. Wiley-blackwell IFT Press, Ames, USA, pp 23-38.

Krischer 0. 1963. Die wissenschaftlichen Grundlagen der Trocknungstechnik (The scientific fundamentals of drying technology). Springer-Verlag, Berlin, Germany.

Maxwell J.C. 1904. Treatise on electricity and magnetism, 3rd ed.
Clarendon Press, Oxford, England.

Michailidis P.A., Krokida M.K., Rahman M.S., 2009. Data and models of density, shrinkage, and porosity. In: Rahman M.S. (ed.), Food properties handbook. CRC Press, Boca Raton, FL, USA, pp 417-500.

Mohsenin N.N. 1980. Thermal properties of foods and agricultural materials. Gordon and Breach Science Publisher, New York, NY, USA.

Murakami E.G., Okos M.R. 1989. Measurement and prediction of thermal properties of foods. In: R.P. Singh \& A.G. Medina (Eds.), Food properties and computer aided engineering of food processing systems. Kluwer Academic Publishers, New York, NY, USA, pp 3-48.

Nesvadba P. 1982. Methods for the measurement of thermal conductivity and diffusivity of foodstuffs. J. Food Eng. 1:93-102.

Rahman M.S., Al-Saidi G.S. 2009. Thermal conductivity prediction of foods. In: M.S. Rahman (eds.), Food properties handbook. CRC Press, Boca Raton, FL, USA, pp 523-649.

Ramaswamy R. Balasubramaniam V.M. Sastry S.K. 2007. Thermal conductivity of selected liquid foods at elevated pressures up to 700 MPa. J. Food Eng. 83:444-51.

Rask C. 1989. Thermal properties of dough and bakery products: a review of published data. J Food Eng. 9:167-93.

Reyes C., Barringer S.A., Uchummal-Chemminian R., Kaletunc G. 2006. Thermal conductivity models for porous baked foods. J. Food Process Pres. 30:381-92.

Sanayei A., Behzadmehe A., Sarvari M.H. 2010. Simulation of digestive biscuit's temperature changes in cooling process applied in Nane Qodse Razavi factory. J. Food Tech. 8:8-13.

Standing C.N. 1974. Individual heat transfer modes in band oven biscuit baking. J. Food Sci. 39:267-71.

Stroshine R.L. 2004a. Physical attributes. In: R.L. Stroshine (ed.), Physical properties of agricultural material and food products. Purdue University Press, West Lafayettte, IN, USA, pp 11-52.

Stroshine R.L. 2004b. Thermal properties and moisture diffusivity. In: R.L. Stroshine (ed.), Physical properties of agricultural materials and food products. Purdue University Press, West Lafayettte, IN, USA, pp 217-38.

Tavman I.H., Tavman S. 1999. Measurement of thermal conductivity of dairy products. J. Food Eng. 41:109-14.

Watson E.L. 1975. Thermal properties of butter. Can. Agr. Eng. 17:68-71. 